\title{
Recensión de Alves Goncalves (2019). Favelización de la psicología. Ensayos sobre la construcción de una perspectiva popular en Psicología
}

Ignacio Dobles Oropeza

Universidad de Costa Rica

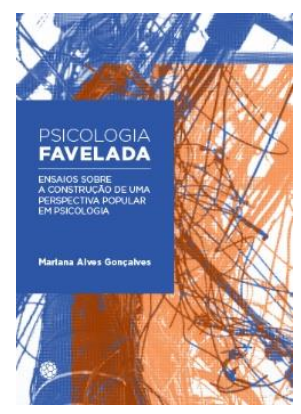

Alves Goncalves, Mariana (2019). Favelización de la psicología. Ensayos sobre la construcción de una perspectiva popular en Psicología. Rio de Janeiro: Mórula Editores.

ISBN: 978-85-65679-86-2

\section{¿PSICOLOGÍA COMUNITARIA PARA QUÉ Y PARA QUIÉN? UNA VALIOSA CONTRIBUCIÓN, DESDE BRASIL}

Lo que se ha conformado como la Psicología comunitaria, o la psicología social comunitaria, ha llenado muchos espacios a lo largo de América Latina, desde su surgimiento a principios de los años setenta del siglo pasado, muy a la mano de los acontecimientos políticos, sociales y culturales de la época (Herrera, 2017). En diferentes lugares del continente se han generado búsquedas, discusiones e inquietudes de quienes han querido vincular el destino de su profesión con el de las comunidades.

En nuestro caso, en la pequeña y a la vez compleja Costa Rica, algunos colegas que intentamos trabajar en lo comunitario publicamos en el año 2017 un libro titulado Miradas sentidas y situadas: experiencias con grupos y comunidades 
(Editorial Universidad de Costa Rica), con 43 autores y reseñas críticas de experiencias de inserción, así como contribuciones, también críticas, a la valoración de la evolución y estado actual de este ámbito socio comunitario (Dobles Oropeza, Maroto Vargas, Masis Méndez y Rodríguez Fernández, 2017). Así como lo hemos hecho nosotros habrá, seguramente, intentos similares en otros lugares del mundo psi.

Quienes hemos acompañado a movimientos sociales, agrupaciones comunitarias ecologistas, agrupamientos de campesinos desplazados o en lucha por la tierra, o a sectores migrantes, poblaciones defendiendo sus territorios ante despojos 0 jóvenes articulando para contribuir a la transformación social, y que, a la vez, intentamos apropiarnos y repensar lo establecido en espacios académicos, hemos sentido una impaciencia creciente a lo largo de los años ante un campo de acción que, en muchos casos, parecía convertirse en un regulador tecnocrático de las acciones de pobladores, imponiendo en clave colonizadora necesidades ajenas, visiones universalistas o mandatos jerárquicos desde lo institucional, y que, además, se empeñaba muchas veces en desligar los ámbitos de acción micro, hipostasiados, de lo macro, o en dibujar un quehacer en que, en el relato divulgador y programático, borraba los dolores y las fracturas, y desplazaba o invisibilizaba la subjetividad de quienes se insertan "desde afuera" en estos campos de acción (Dobles, 2017). Se trabajaba, muchas veces, sobre las necesidades y carencias percibidas de pobladorxs, no de sus aspiraciones y proyectos.

A esto debemos agregar el peligro de un "nominalismo" que, como advertía hace un par de décadas la psicóloga colombiana María Clemencia Castro (1993), delimita el espacio comunitario como "propio" de la psicología, desarrollando una cultura y una institucionalidad que define lo que es y lo que no es psico-comunitario.

Paradójicamente, como ha argumentado Nicolás Herrera (2017), una psicología comunitaria latinoamericana que se fortaleció en los años setenta con un impulso ético-político y un horizonte utópico, de ruptura, y que, además, lo hizo con el propósito de potenciar comunidades y no a la acción extensionista de las instituciones establecidas, se ve cercada por acomodos, por mandatos tecnocráticos, y por su ausencia en acontecimientos claves e intentos transformadores en lo macro.

En este contexto, la psicóloga brasileira Mariana Alves Goncalves irrumpe con una contribución clave, vigorosa, comprometida, para ser leída y pensada. Se nutre de planteamientos de Martín-Baró y otrxs, pero - sobre todo- se nutre de los relatos, las circunstancias, las vivencias, de sectores populares con los que ha trabajado en la ciudad brasileña. 
En sus ensayos, que tratan de los desafíos que encuentra una psicología que busque entrelazarse con lo popular, hace un recorrido sobre el desarrollo de la Psicología Social Comunitaria en Brasil, que ha hecho contribuciones importantes, pero que al mismo tiempo adolece de limitaciones debidamente señaladas por la autora. Tornarse "popular", escribe:

Significa salir de sus lugares teóricos y ético políticos. Esa apuesta significa que el movimiento de encontrar espacios sociales marginalizados debería significar una transformación de la psicología y no una extensión de sus servicios a las mayorías populares. (Alves Goncalves, 2019, p. 52)

Apunta, la autora, a una idea-fuerza fundamental, articulada desde las vivencias y las necesidades de quienes viven la experiencia vital de las favelas: no se trata de pensar una psicología, con todo lo que eso implica: acciones, conceptualizaciones, metodologías, etc. para las favelas (las críticas que esboza son poderosas, incluyendo el peligro de mercantilizar la propia acción en estos ámbitos), sino el desafío de favelizar la psicología, lo que a mi entender conlleva vincular la acción del psicólogo o la psicóloga con las aspiraciones, las vivencias, las creaciones, los dolores, las fracturas, de los sectores populares. Escribe la autora: "la defensa no es la de una psicología que extienda su mano al pueblo, sino de una que se construya a partir de este, y se deje poblar por su lucha" (Alves Goncalves, 2019, p. 78).

¿Qué es lo popular? Esto, evidentemente, conduce a muchos debates acerca del concepto pueblo, que no podemos desglosar a cabalidad aquí. Creo que se trata, en este caso, de aquellos sectores vulnerabilizados, muchas veces acosados y acechados, que sufren la opresión, la explotación o la discriminación en contextos sociales adversos e injustos. Favelizar la psicología implica, claramente, no instrumentalizar a la psicología para aplicarla en el espacio de lo popular, sino transformarla, pensando y actuando desde otro lugar.

Por otro lado, la autora efectúa dos críticas aleccionadoras centrales a lo que ha sido el desarrollo de la psicología comunitaria en su país, Brasil. Por un lado, en consonancia con algo que ya he tratado, denosta el desarrollo de un "especialismo" creciente que hace que la psicología no se abra al mundo de lo popular, relativizando sus posicionamientos ético-políticos y, en consecuencia, cercándose así a sí misma. A la psicología, escribe, "le hace falta un baño de favela" (Alves Goncalves, 2019, p. 35).

Por otro lado, critica lo que considera es un acercamiento creciente a la psicología positiva, con sus peligrosos mandatos y los imperativos culturales que fomenta. Considera que esta tendencia tiende a individualizar la experiencia, disminuye el talante crítico de la disciplina, y puede terminar configurando otra de nuestras preocupaciones en el 2017: la de presentar un campo de acción posible 
de la psicología (la comunitaria), en "bonito" excluyendo o minimizando, de nuevo, los dolores, los sufrimientos, las fracturas (Dobles, 2017).

La autora aboga claramente por una psicología historizada, situada, que sea parte activa de esta historia y de su contexto, vinculada a las "inquietudes transformadoras" de quienes sufren y dejándose marcar por ellas. Es una contribución que merece ser discutida, trabajada, y que tendrá mucho que decir para quienes en psicología ponen la mira (y las manos) en la justicia y la transformación social profunda.

La función de quien establece una reseña de un texto tan sugerente y pertinente, además de comprometido, implica, a mi juicio, extender una invitación a las personas que nos leen: es decir, propiciar que se sienten compelidas a revisar por su propia cuenta el libro que he venido comentando. Háganlo, realmente, háganlo. Encontraran muchísimos elementos e intuiciones que ayudan a acercarse a la meta explicitada por la autora: La de lograr crear una psicología con perspectiva popular. Me parece muy acertado que lo denomine así: una psicología con una perspectiva que acerca a las "virtudes populares" que destacaba Ignacio Martín-Baró (ver Dobles, 2016), y no una psicología que se autodefine a priori como "popular". Hay mucho que discutir, mucho que trabajar. Tenemos mucho que agradecer a Mariana Alves Goncalves.

\section{REFERENCIAS}

Alves Gonçalves, Mariana (2019). Psicología favelada. Ensayos sobre la construcción de una perspectiva popular en Psicología. Rio de Janeiro: Mórula Editores.

Castro, María Clemencia (1993). La psicología, los procesos comunitarios y la interdisciplinariedad. Guadalajara: Universidad de Guadalajara.

Dobles Oropeza, Ignacio (2016). Ignacio Martín-Baró. Una lectura en tiempos de quiebres y esperanzas. San José: Editorial Arlekín.

Dobles Oropeza, Ignacio (2017). Delimitación disciplinaria y poder: algunas discusiones necesarias en el campo de la psicología comunitaria. En Ignacio Dobles Oropeza, Adriana Maroto Vargas, María José Masis Méndez \& Adriana Rodríguez Fernández (Eds.), Miradas Sentidas y situadas. Experiencias con grupos y comunidades (pp. 2543). San José: Editorial Universidad de Costa Rica.

Dobles Oropeza, Ignacio; Maroto Vargas, Adriana; Masis Méndez, María José \& Rodríguez Fernández, Adriana (Eds.) (2017). Miradas Sentidas y situadas. Experiencias con grupos y comunidades. San José: Editorial Universidad de Costa Rica.

Herrera Farfan, Nicolas (2017). ¡Al banquillo! La psicología comunitaria latinoamericana vista desde la psicología de la Liberación. En Ignacio Dobles Oropeza, Adriana Maroto Vargas, María José Masis Méndez \& Adriana Rodríguez Fernández (Eds.), Miradas Sentidas y situadas. Experiencias con grupos y comunidades (pp. 3-24). San José: Editorial Universidad de Costa Rica. 
Ignacio Dobles Oropeza

Docente e investigador. Trabaja psicología social, metodología cualitativa, psicología política y comunitaria, y psicología de la liberación.

doblesignazio@gmail.com

\section{FORMATO DE CITACIÓN}

Dobles Oropeza, Ignacio (2020). Recensión de Alves Goncalves (2019). Favelización de la psicología. Ensayos sobre la construcción de una perspectiva popular en Psicología. Quaderns de Psicologia, 22(2), e1661. http://dx.doi.org/10.5565/rev/qpsicologia.1661 